\title{
Long-term urological management in spinal injury units in the UK and Eire: a follow-up study
}

\author{
JR Burki, I Omar, PJR Shah and R Hamid
}

\begin{abstract}
Aims: The majority of patients with spinal cord injury (SCI) will develop neurogenic lower urinary tract dysfunction (NLUTD). These patients require a long-term urological follow-up. The follow-up protocol has varied across SCl units in the United Kingdom and Eire. We reviewed the long-term management in the $\mathrm{SCl}$ units to identify changes in practice over a decade and compared them to current guidelines.

Methods: We present results of a review of all SCI centres in the United Kingdom and Eire on their long-term urological management before and after the current guidelines and compared the results with European Association of Urology (EAU) Guidelines on NLUTD and the proposed British guidelines for the urological management of patients with $\mathrm{SCl}$. Data were collected through questionnaires posted to $\mathrm{SCl}$ units.

Results: $\mathrm{SCl}$ patients are followed up in outpatients annually in the $\mathrm{SCl}$ centres and the frequency of follow-up remains largely unchanged. More $\mathrm{SCl}$ units perform renal tract imaging annually as a part of $\mathrm{SCl}$ follow-up. Most units follow the proposed British guideline indications for urodynamics and do not perform 'routine urodynamics'.

Conclusions: We conclude that the long-term management of SCl patients in $\mathrm{SCl}$ units in the United Kingdom and Eire has changed overtime to follow the proposed British guidelines. EAU guidelines offer a more extensive follow-up regime. Last, there is a continued lack of high-quality evidence to support an optimal long-term follow-up protocol. Importantly, there is a lack of evidence on clinical outcomes when these guidelines have been followed.
\end{abstract}

Spinal Cord (2014) 52, 640-645; doi:10.1038/sc.2014.90; published online 10 June 2014

\section{INTRODUCTION}

The annual incidence of spinal cord injury (SCI) is up to 40 cases per million. ${ }^{1}$ Most of these patients develop neurogenic lower urinary tract dysfunction (NLUTD). ${ }^{2}$ Mortality due to urological complications has decreased over recent years, ${ }^{3}$ due to meticulous attention to the kidneys and bladder. Long-term urological follow-up is needed to optimise the bladder by low-pressure filling and complete bladder emptying. Restoration of continence is a goal for improved quality of life. ${ }^{4}$ SCI patients are best managed in a SCI centre with integrated facilities for rehabilitation and a multidisciplinary approach: involving urologists, rehabilitation specialists, specialist nurses and physiotherapists etc. ${ }^{5}$ Although it is agreed that patients with NLUTD should have regular follow-up, there is little concusses how this should be monitored over the long-term to detect urological complications. ${ }^{6}$

We conducted a survey of SCI units in 2004 to evaluate the longterm urological management of SCI patients in the United Kingdom and Eire, which showed a considerable variation in urological practice among SCI centres in the United Kingdom and Eire. ${ }^{7}$ Since then guidelines have been published on the management of NLUTD, and NLUTD in association with SCI. These include the European Association of Urology (EAU) guidelines for management of NLUTD, ${ }^{4}$ proposed British guidelines for the urological management of patients with $\mathrm{SCI}^{5}$ and the consortium for spinal cord medicine in the United States. ${ }^{8}$
There seems to be a consensus among all the guidelines on the immediate and short-term management of SCI patients as is the agreement for the need for lifelong follow-up to preserve renal function, prevent complications, promote continence and improve quality of life. ${ }^{4,5}$ However, the frequency of follow-up and investigations undertaken reveal considerable variation among these guidelines.

We conducted a repeat survey of 12 SCI units in the United Kingdom and Eire on their current neuro-urological practice on the long-term follow-up of SCI patients and evaluated the change in management over the years in the light of EAU guidelines on NLUTD and proposed British guidelines.

\section{MATERIALS AND METHODS}

We sent the same questionnaire as in the earlier study ${ }^{7}$ to the consultant urologists at the $12 \mathrm{SCI}$ centres in the United Kingdom and Ireland (Appendix). If the filled questionnaire was not received after 1 month, a second questionnaire was sent. Not receiving the questionnaire the second time a telephone contact was made and a third questionnaire was sent. A further telephonic contact was made for information on general setup.

The questionnaire addressed the general setup, management of urinary tract infections, outpatient follow-up, upper tract surveillance and urodynamics.

\section{RESULTS}

There was a $100 \%$ reply rate (12/12). Eight SCI centres replied on the receipt of the first questionnaire. The SCI centres contacted are listed in Table 1. 


\section{General setup}

Overall, 12 urology consultants cover the spinal injury units. Three consultants work full time and nine work part time. Six units do not have a urology registrar, five have one registrar and one has two registrars. Six units employ urology nurse specialists, with a total of 13 nurse specialists in all units. The maximum number of nurse specialists in a unit was four.

The number of acute and rehabilitation beds in the SCI centres range from 28 to 113 (mean 50.5). National SCI centre, Stoke Mandeville has the largest number of beds. All SCI centres offer regular outpatients follow-up and urological surgery as appropriate at either the SCI centre or the affiliated hospital.

\section{Urology outpatient review}

In eight SCI units, the follow-up is performed by urologists. In three units, follow-up for SCI patients is performed by the rehabilitation team and referred to urology for intervention. One unit shares the follow-up with rehabilitation team.

Seven units offer annual urological review to patients with suprasacral lesions. The remaining five units did not comment separately on the follow-up of suprasacral and infrasacral lesions. Patients with infrasacral lesions are seen annually in four units, 18 monthly in one unit and 2 yearly in two units.

Table 2 gives a comparison of current outpatients follow-up in SCI units with the previous survey in 2004. ${ }^{4}$ The recommended outpatient follow-up as per EAU and proposed British guidelines is also shown.

\section{Renal tract imaging}

All units undertake renal tract imaging in the follow-up of SCI patients (Table 3). Seven units perform ultrasound kidney, ureters and bladder (KUB), three units perform ultrasound and X-ray KUB, one unit performs ultrasound KUB or intravenous urography and one unit performs a baseline and 3 yearly renogram, in addition to ultrasound KUB.

In suprasacral lesions, 10 units perform annual upper tract imaging, 1 unit after initial annual imaging performs 2 yearly imaging and on1 unit performs 1-3 yearly imaging. In infrasacral lesions, seven units perform annual imaging, one initially annually then 2 yearly, one 18 monthly, one 2 yearly and one $1-3$ yearly. One unit decides on imaging according to patient's clinical presentation. Table 3 provides a comparison between the surveys and the guidelines.

\section{Table 1 An alphabetical list of $\mathrm{SCl}$ centres in the United Kingdom} and Eire

Duke of Cornwall SCl centre, Salisbury

James cook University Hospital, Middlesbrough

London SCl centre, Stanmore, London

Midlands centre for $\mathrm{SCl}$

National SCl centre, Stoke Mandeville, Aylesbury

National Centre for SCI, Dublin

North Wales SCl centre, Southport

Princess Royal SCl centre, Sheffield

Scottish National SCl centre, Glasgow

$\mathrm{SCl}$ Centre, Musgrave Park, Belfast

Welsh SCl centre, Cardiff

Yorkshire SCI centre, Wakefield

Abbreviation: $\mathrm{SCl}$, spinal card injury.

\section{Urodynamic studies}

Ten units perform videourodynamics (VCMG), one does standard urodynamics and one unit did not comment on the type of urodynamics undertaken. These are performed by urologist in six units, specialist nurses in three units, rehabilitation team in two and General Practitioner (GP) with special interest in urodynamics in one unit.

In patients with suprasacral lesions, 10 units do not perform routine urodynamics, 1 unit performs annually, whereas 1 does so every 2-3 years. Only one unit undertakes VCMG yearly in patients with infrasacral lesions. These are summarised in Table 4 along with comparisons.

\section{Recurrent urinary tract infection (UTI)}

The duration of antibiotic treatment for UTI ranges between 3 and 10 days. Only three units had a unified departmental protocol for treatment of recurrent symptomatic UTI. No unit routinely treats asymptomatic UTI in patients with indwelling catheters. One unit treats asymptomatic UTI in patients on intermittent self-catheterisation. Ten units treat recurrent UTI with antibiotics. The choice of self start and long-term prophylaxis varies among the SCI units (Table 5).

\section{DISCUSSION}

We evaluated the current long-term management of NLUTD in SCI patients within the SCI centres in the United Kingdom and Eire and compared the same to the survey undertaken about 10 years ago. ${ }^{7}$ In addition, the current long-term management was compared with the published guidelines for compliance. The EAU guidelines ${ }^{4}$ are not SCI specific but include SCI-associated NLUTD. The proposed British Guidelines ${ }^{5}$ are SCI specific but mostly based on expert opinion rather than level 1 evidence. In addition, we looked into management of recurrent UTI again as our previous survey highlighted a variation in the management.

\section{Urology outpatient review}

SCI patients require a regular lifelong follow-up. They are prone to numerous urological problems, such as catheter-related problems, including bladder tumours, ${ }^{9}$ UTI, ${ }^{10}$ urolithiasis ${ }^{11}$ and hydronephrosis $^{12}$ leading to renal impairment.

Majority of the units review patients with suprasacral SCI on an annual basis, whereas patients with infrasacral SCI are reviewed 2 yearly. This is different to what was practiced at the time of first survey where regardless of the level of injury the majority of patients were reviewed annually. The increase in number of patients to be followed up may have a role in prioritising unsafe bladders with suprasacral lesions to be followed more closely as compared with patients with infrasacral lesions, which are more likely to have safe bladders. In United States of America, the urological evaluation is done every year according to the Paralysed Veterans of America guidelines 2009. ${ }^{6}$

The EAU and proposed British guidelines recommend that urological care of a neuropathic bladder should be undertaken by urologist either working in SCI unit or in a hub and spoke fashion. In majority of units, the urological care is provided by the urologist, whereas three units follow SCI patients by rehabilitation team and refer to urologist when required. Comprehensive outpatient health care in SCI patients has an association with higher subjective health levels, increased independence and improved psychological wellbeing. ${ }^{13}$ It would be reasonable to incorporate similar approach into urological care. Despite the importance of regular urological follow-up, compliance is frequently a problem in SCI. The most 
Table 2 Frequency of outpatient follow-up in spinal injury units

\begin{tabular}{|c|c|c|c|c|}
\hline Frequency of follow-up & $\begin{array}{l}\text { Number of units } \\
2004\end{array}$ & $\begin{array}{l}\text { Number of units } \\
2013\end{array}$ & EAU Guidelines & Proposed British Guidelines \\
\hline Only as required & 2 & & $\begin{array}{l}\text { Physical Ex, Biochem and urine } \\
\text { laboratory }\end{array}$ & 6 Months \\
\hline Every 6 months & 1 & & Yearly & 12 Months and then yearly \\
\hline Annually & 6 & 5 & & $\begin{array}{c}\text { Creat clearance at } 12, \text { sm.creat } \\
\text { thereafter }\end{array}$ \\
\hline 1-2 Yearly & 1 & & & \\
\hline $1-5$ Yearly & 1 & & & \\
\hline $\begin{array}{l}\text { Annually; biannually if stable or more than } 10 \text { years } \\
\text { since injury }\end{array}$ & 1 & 1 & & \\
\hline Yearly for SSL, $18 \mathrm{~m}$ for ISL & & 1 & & \\
\hline Yearly for SSL, 2 years for ISL & & 2 & & \\
\hline Yearly by rehab team & & 3 & & \\
\hline
\end{tabular}

Abbreviations: EAU, European Association of Urology; ISL, infrasacral lesions; sm. creat, serum creatinine; SSL, suprasacral lesions.

Table 3 Frequency of upper tract surveillance in spinal injury units

\begin{tabular}{lcccc}
\hline $\begin{array}{l}\text { Frequency of renal } \\
\text { tract imaging }\end{array}$ & $\begin{array}{c}\text { Number of } \\
\text { units in 2004 }\end{array}$ & $\begin{array}{c}\text { Number of } \\
\text { units in 2013 }\end{array}$ & $\begin{array}{c}\text { EAU } \\
\text { Guidelines }\end{array}$ & $\begin{array}{c}\text { Proposed British } \\
\text { Guidelines }\end{array}$ \\
\hline $\begin{array}{l}\text { Annually } \\
\text { Every 18 months }\end{array}$ & 9 & 10 & 6 Monthly & Yearly \\
Biannually & 1 & 1 & & \\
Every 3 years & 1 & 1 & & \\
Annually, then & & & \\
biannually & & & \\
$1-3$ yearly & & &
\end{tabular}

Abbreviation: EAU, European Association of Urology.

important variables in non-compliance include cost, distance, transportation and the belief that follow-up is not necessary. ${ }^{14}$

\section{Renal tract Imaging}

Frequent surveillance of renal tract is recommended for timely diagnosis of impending problems with a potential to permanently impair renal function. ${ }^{15}$ The type of imaging modality used by the majority of units for surveillance is ultrasound. It is encouraging to note that $83.3 \%$ units perform ultrasound scan annually. This is keeping in line with proposed British guidelines but fall short of EAU guidelines, which recommends US imaging for upper tract, bladder morphology and residual urine check biannually. The remaining two units will perform US scan once every $2-3$ years. Ultrasound imaging can detect upper tract dilatation, which should be investigated with a MAG3 scan and VCMG. ${ }^{16}$ There is no evidence to suggest the impact on long-term outcomes comparing ultrasound imaging performed on a yearly or a 6 monthly basis. It appears at the present time that yearly ultrasound (USS) in SCI patients to assess for potential complications is safe, ${ }^{17}$ sensitive and cost effective. ${ }^{18}$ Indeed, in a recent systematic review, this was the only recommendation based on current evidence. ${ }^{6}$

\section{Urodynamics}

History and clinical examination cannot be relied upon to determine optimal urological management strategy in patients with NLUTD. ${ }^{19}$ Urodynamic studies have a pivotal role in bladder management of SCI patients. VCMG is considered the gold standard investigation for assessment of NLUTD. ${ }^{4}$ It adds additional information relating to changes in the detrusor, vesico-ureteric reflux and stress incontinence. $^{20}$

Ten units perform VCMG for initial evaluation of lower urinary tract. But only one unit performs this annually as part of follow-up. Another unit performs VCMG in reflex voiders every 2-3 years. The remaining 10/12 units only perform VCMG when clinically indicated. This has changed from 6/12 units in 2004 performing VCMG when clinically indicated. ${ }^{7}$ It appears this change has been instituted as a result of proposed British guidelines, which do not recommend routine urodynamics. This is in variation to EAU guidelines, which states that urodynamics should be performed every 1-2 years and when risk factors emerge. The frequency of urodynamics undertaken may be dictated by the availability of resources.

This inconsistency in recommendation for urodynamics in longterm management of SCI patients in different guidelines is a result of lack of evidence of the value of sequential urodynamic studies and their impact on change in management in NLUTD. This is supported by a recent study that demonstrated yearly USS to be safe in patients who had a safe lower urinary tract and were undertaking intermittent self-catheterisation ${ }^{21}$. However, other studies have shown that regular VCMG can lead to a change in bladder management in a significant proportion of patients. ${ }^{22,23}$ There no evidence on the long-term outcomes comparing regular urodynamics to performing urodynamics based on clinical grounds.

The bladder has conventionally been called 'the unreliable witness' $^{24}$ due to lack of consistency in the symptoms associated with dysfunction. We feel that the same holds true for neuropathic bladders. There is a need for well-designed long-term studies to establish the impact of long-term regular urodynamics on clinical outcomes in SCI patients.

\section{UTI}

UTI is a major cause of morbidity and mortality in SCI patients. ${ }^{10}$ The risk factors for UTI include cervical level cord injury, long-term catheters, neurogenic detrusor overactivity, detrusor sphincter dysynergia and vesicoureteric reflux. ${ }^{25}$ The high incidence of UTI in SCI patients can be due to a combination of these factors.

No unit is treating asymptomatic UTI in patients with catheters, whereas only one treats asymptomatic UTI in patients with selfcatheterisation. Except the later, this is in keeping with EAU guidelines that states that neither patients with indwelling catheter nor selfcatheterisation should be treated with antibiotics if asymptomatic. 
Table 4 Frequency of routine urodynamic studies in spinal injury units

\begin{tabular}{|c|c|c|c|c|}
\hline Frequency of study & $\begin{array}{l}\text { Number of units in } \\
\qquad 2004\end{array}$ & $\begin{array}{l}\text { Number of units in } \\
\qquad 2013\end{array}$ & EAU Guidelines & $\begin{array}{c}\text { Proposed British } \\
\text { Guidelines }\end{array}$ \\
\hline Only as required or indicated & 6 & 10 & $\begin{array}{c}\text { VCMG every } 1-2 \text { years and when risk factors } \\
\text { emerge }\end{array}$ & As indicated \\
\hline Only once in rehabilitation & 1 & 1 & & \\
\hline Annually & 1 & 1 & & \\
\hline $\begin{array}{l}\text { Annually; biannually if stable or more than } 10 \text { years } \\
\text { since injury }\end{array}$ & 1 & & & \\
\hline After 3 months, then annually & 1 & & & \\
\hline Only in reflex voiders (2-3 yearly) & 1 & & & \\
\hline Annually in reflex voiders, 3 yearly in others & 1 & & & \\
\hline
\end{tabular}

Abbreviations: EAU, European Association of Urology; VCMG, videourodynamics.

Table 5 Treatment of recurrent UTI in SCl patients in the United Kingdom and Eire

Antibiotics given for recurrent UTI

Self start

Daily antibiotics

Either

10 Units

3 Units

5 Units

Abbreviations: $\mathrm{SCl}$, spinal cord injury; UTI, urinary tract infection.

The treatment of symptomatic UTI is clearer and treatment should involve the use of narrow spectrum antibiotic for a shortest possible duration. ${ }^{26}$ Antibiotic prophylaxis for recurrent UTI was practiced by $10 / 12$ units, however, it appears that each unit was treating this problem differently. Majority of the units 8/12 (66\%) give prophylactic antibiotics; this is in keeping with EAU guidelines. Perhaps the most important factor in the prevention of symptomatic UTI in SCI patients is the method of bladder emptying, specifically the avoidance of permanent catheterisation.

The duration of treatment of UTI in the early survey was 3-14 days $^{7}$ and is $3-10$ days in the repeat survey. This is broadly keeping in line with EAU guidelines, which recommend treatment for complicated UTI for 7-14 days.

This paper has its limitations as a questionnaire-based study; audits at the individual units can accurately reflect the actual neurourological practice. The questionnaire was not standardised but the same questionnaire as in the earlier study ${ }^{4}$ was used for consistency and to evaluate change in practice.

This study does not look into the short- and intermediate-term management of SCI patients. It appears that the guidelines recommendations for managing NLUTD in short- and intermediate-term are relatively comparable, but there is significant variation in the longterm management. Hence, we decided to undertake the study to highlight the impact of these variations on the clinical management protocols in SCI units in the United Kingdom and Eire. In addition, the outcomes were not evaluated as part of the study. It was thought that it would not be possible to evaluate the outcomes on a basis of a questionnaire-based study. The reasons for following wing a specific guideline were not investigated.

\section{CONCLUSION}

The aim of this study was to survey the long-term urological management in the SCI centres in the United Kingdom and Eire against current guidelines and identify changes over the last 10 years. This study demonstrates that there has been a significant change in the management of NLUTD in SCI patients as compared with the survey a decade ago. Majority of the SCI units comply with proposed British guidelines on renal tract imaging and urodynamics. However, there remains a significant variation in the frequency of and the physician undertaking the follow-up and treatment of recurrent UTIs. There is a lack of level 1 evidence to support the clinical outcomes when these guidelines have been followed; hence the variation.

\section{DATA ARCHIVING}

There were no data to deposit.

\section{CONFLICT OF INTEREST}

Mr R Hamid is an advisor and lectures for Allergan, Pfizer and Astellas, Mr J Shah is an advisor and lectures for Pfizer, Allergan and AMS. The remaining authors declare no conflict of interest.

1 Sekhon LH, Fehlings MG. Epidemiology, demographics and pathophysiology of acute spinal cord injury. Spine 2001; 15: 2-12.

2 Burns AS, Rivas DA, Ditunno JF. The management of neurogenic bladder and sexual function after spinal cord injury. Spine (Phila Pa 1976) 2001; 26: 129-136.

3 Frankel HL, Coll JR, Charlifue SW, Whitenneck GG, Gardner BP, Jamous MA et al. Long-term survival in spinal cord injury: a fifty year investigation. Spinal Cord 1998; 4: 266-274.

4 Stóhrer M, Blok B, Castro-Diaz D, Chartier-Kartler E, Del Popolo G, Kramer G et al. EAU Guidelines on Neurogenic Lower Urinary Tract Dysfunction. Eur Urol 2009; 56 : 81-88.

5 Abrams P, Agarwal M, Drake M, El-Masri W, Fulford S, Reid S et al. A proposed guideline for the urological management of patients with spinal cord injury. BJU Int 2008; 101: 989-994.

6 Cameron AP, Rodriguez GM, Schomer KG. Systematic review of urological followup after spinal cord injury. J Urol 2012; 187: 391-397.

7 Bycroft J, Hamid R, Bywater H, Patki P, Craqqs M, Shah J. Variation in urological practice amongst Spinal Injuries Units in UK and Eire. Neurourol Urodynamics 2004; 23: $252-256$

8 Consortium for Spinal Cord Medicine. Bladder Management for Adults with Spinal Cord Injury. A clinical practice guideline for health- care providers. Consortium for Spinal Cord Medicine, Paralysed Veterans of America 2006; 29: 527-573.

9 Groah SL, Weitzenkamp DA, Lammertse DP, Whiteneck GG, Lezotte DC, Hamman RF. Excess risk of bladder cancer in spinal cord injury: Evidence for an association between indwelling catheter use and bladder cancer. Arch Phys Med Rehabil 2002; 83: 346-351.

10 Trautner BW, Darouiche RO. Prevention of urinary tract infection in patients with spinal cord injury. J Spinal Cord Med 2002; 25: 277-283.

11 DeVivo MJ, Fine RR, Cutter GR, Maetz HM. The risk of bladder calculi in patients with spinal cord injuries. Arch Intern Med 1985; 145: 428-430.

12 Shingleton WB, Bodner DR. The development of urologic complications in relationship to bladder pressure in spinal cord injured patients. J Am Paraplegia Soc 1993; 16: 14-17.

13 Dunn M, Love L, Revesloot C. Subjective health in spinal cord injury after outpatient health care follow-up. Spinal Cord 2000; 38: 84-91.

14 Canupp KC, Waites KB, DeVivo MJ, Richards JS. Predicting compliance with annual follow up evaluations in persons with spinal cord injury. Spinal Cord 1997; 35: 314-319.

15 Bodley R. Imaging in chronic spinal cord injury ? indications and benefits. Eur J Radiol 2002; 42: 135-153. 
16 Burki JR, Abdul-Rahman A, Hamid R, Shah PJR. Significance of upper tract abnormalities identified on ultrasound during followup of neurogenic bladder patients. Poster no 6, BAUS Annual Meeting 2011, Published in BJU International 108: 18-60.

17 Bih LI, Tsai SJ, Tung LC. Sonographic diagnosis of hydronephrosis in patients with spinal cord injury: influence of bladder fullness. Arch Phys Med Rehabil 1998; 79: 1557-1559.

18 Vaidyanathan S, Hughes PL, Soni BM. A comparative study of ultrasound examination of urinary tract performed on spinal cord injury patients with no urinary symptoms and spinal cord injury patients with symptoms related to urinary tract: do findings of ultrasound examination lead to changes in clinical management? Sci World J 2006; 6: 2450-2459.

19 Wyndaele JJ. Correlation between clinical neurological data and urodynamic function in spinal cord injured patients. Spinal Cord 1997; 35: 213-216.

20 Foley SJ, McFarlane JP, Shah PJ. Vesicoureteric reflux in adult patients with spinal injury. Br J Urol 1997; 79: 888-891.
21 Edokpolo LU, Foster HE Jr. Renal tract ultrasonography for routine surveillance in spinal cord injury patients. Top Spinal Cord Inj Rehabil. Winter 2013; 19: 54-60.

22 Linsenmeyer TA, Linsenmeyer MA. Impact of annual urodynamic evaluations on guiding bladder management in individuals with spinal cord injuries. J Spinal Cord Med 2013; 36: 420-426.

23 Patki P, Woodhouse J, Hamid R, Shah J, Craggs M. Lower urinary tract dysfunction in ambulatory patients with incomplete spinal cord injury. J Urol 2006; 175: 1784-1787; discussion 1787

24 Warwick RT, Whiteside CG, Arnold EP, Bates CP, Worth PH, Milroy EG et al. A urodynamic view of prostatic obstruction and the results of prostatectomy. $\mathrm{Br} \mathrm{J}$ Urol 1973; 45: 631-645.

25 Esclarin DR, Garcia LE. Herruzo CR. Epidemiology and risk factors for urinary tract infection in patients with spinal cord injury. J Urol 2000; 164: 1285-1289.

26 Siroky MB. Pathogenesis of bacteriuria and infection in the spinal cord injured patient. Am J Med 2002; 113: 67-79. 


\section{APPENDIX}

Audit of urological management of patients with spinal cord injuries in spinal injury units in the UK and Eire

1. Do you have a unified department or unit protocol for the treatment of recurrent symptomatic UTI in patients with SCI?

YES

NO

Comments

2. Do you routinely treat asymptomatic UTI in patients with

Indwelling catheters YES NO Comments.....

Intermittent catheters YES NO Comments....

3. Do you advocate prophylactic antibiotics for recurrent UTI?

YES NO

If yes do you prefer to advise self start course of antibiotics or a prophylactic daily dose. Comments

4. How many days do you treat UTI for?

No of days

Comments.

5. How frequently do you perform routine upper tract imaging?

Frequency

In Supra-sacral lesions

In Infra-sacral lesions.

Type of Imaging.

Comments.

6. How frequently do you f perform routine urodynamics? Frequency

In Supra-sacral lesions

In Infra-sacral lesions.

Video OR standard UDS

Comments.

7. Who performs the urodynamics?

Urologist/urology registrar

Nurse Specialist....

8. How frequently do you perform routine urology review in outpatients?

Frequency

In Supra-sacral lesions

In Infra-sacral lesions

Comments

9. Do you have a dedicated Neuro-urologist attached to Spinal cord injury Unit?

YES

NO

If yes

Number of neuro-ulrologists.

Full time.

Part time

10. How many urology registrars work in the unit?

Training registrars.

Clinical/Research Fellows

Full time.

Part time.

11. Do you have Clinical nurse specialists working for the unit?

YES $\mathrm{NO}$

If Yes, How many

Please could you complete this form and fax to

Many thanks for your assistance with this. 